\title{
A single-centre study of 1000 consecutive peribulbar blocks
}

\begin{abstract}
Purpose To assess the efficacy and safety of the peribulbar block as practised by anaesthetists in a District General Hospital and also to assess the effect of using the 'painless local' subconjunctival injection on the pain of the peribulbar block.

Method Audit data collected from 1000 consecutive patients undergoing peribulbar blocks with $2 \%$ lignocaine were analysed. Efficacy was assessed by visual rating scores for operative pain, eye movement, intraocular pressure and reinjection rate, and safety by looking at complications. Comparison of pain of injection scores was used to assess the effect of the 'painless local' injection. Visual rating scores for pain were analysed using the Mann-Whitney U-test.

Results Akinesia was achieved in $79 \%$ of blocks and operative pain scores were very low (median = 0, IQR = 0). All complications recorded were minor and there were no sightor life-threatening events. The 'painless local' injection given to 499 patients resulted in significantly lower visual rating scores for pain of injection $(p<0.05)$.

Conclusion These data suggest that the peribulbar block is a safe and effective method of providing anaesthesia for eye surgery provided that it is taught methodically and practised by experienced staff. The

'painless local' injection reduces the pain experienced during administration of this block.
\end{abstract}

\section{J. Budd}

M. Hardwick

K. Barber

J. Prosser

Worcester Royal Infirmary Worcester WR5 1HN, UK

\section{Dr J. Budd $\bowtie$}

Department of Anaesthesia Worcester Royal Infirmary Newtown Road Worcester WR5 1HN, UK Tel: +44 (0)1905 760637 Fax: +44 (0)1905 760811 e-mail: jandphughes@tesco.net

Part of this work was presented at the British Ophthalmic Anaesthetists Society meeting, June 1999

Received: 6 March 2000 Accepted in revised form: 5 September 2000
Key words Anaesthetic techniques, regional, peribulbar; Anaesthetics local, lignocaine

The peribulbar block was first described in 1986 by Davis and Mandel. ${ }^{1}$ Its introduction as a safe alternative to the retrobulbar block, together with a move to increase the number of cataracts done as day cases, led to a swing in favour of local anaesthesia for eye surgery and away from the traditional practice of general anaesthesia in the UK. In addition the recommendations of the Joint Working Party of the Royal College of Anaesthetists and the College of
Ophthalmologists in $1993^{2}$ for the involvement of anaesthetists has meant that they are increasingly performing peribulbar blocks.

Although large series of peribulbar blocks given by anaesthetists in the United States and Canada have reported low incidence of complications, ${ }^{3,4}$ recent reports of globe perforations during peribulbar blocks in the UK have led some ophthalmologists to question the involvement of anaesthetists and the safety of the peribulbar block. ${ }^{5}$

In Worcester, peribulbar blocks have been used successfully since 1989, and in $199798 \%$ of cataract extractions were performed under local anaesthesia with $95 \%$ of patients treated as day cases.

\section{Organisation of service}

The aim of the ophthalmology team in Worcester is to run an efficient service with a day case rate of at least $90 \%$. With few exceptions patients are listed for local anaesthesia as a day case on their first outpatient visit. Before surgery, patients are fully informed of the anaesthetic technique and operative procedure through detailed explanation by a nurse and from being shown video. On the working day before surgery they attend outpatients for their immediate preoperative preparation when an anaesthetic assessment form is completed, consent signed and pre-operative eye drops prescribed. They are then given sequential admission times to the day case ward on the day of surgery so that they arrive approximately $30 \mathrm{~min}$ before their expected theatre time. They are not starved and no pre-operative investigations are done unless specifically indicated. Warfarin is continued provided the International Normalised Radio (INR) is within the therapeutic range $(<3.5)$. On arrival at the day case unit they are prepared for theatre and walk to the anaesthetic room. The peribulbar block is given by an anaesthetist and the patient is then transferred to theatre where surgery is performed by one of two consultant surgeons. Drapes covering the patient's face are kept to a minimum and supplemental oxygen is administered. A nurse reassures the patient throughout surgery and a pulse oximeter is used to monitor oxygen saturation and pulse 
rate. Once surgery is completed, patients walk or are wheeled back to the day case unit where they have tea, complete visual rating scores for pain and are discharged to appropriate care approximately $2 \mathrm{~h}$ after arrival.

Following discharge all patients have open access to the clinic if they encounter any problems during the first week. They are all routinely followed up at 4 weeks postoperatively when assessment includes best corrected acuity, refraction and slit-lamp examination. An examination of the fundus is carried out if any abnormality is discovered.

Anaesthetists in training are given thorough instruction and demonstration of the block by one of two consultant anaesthetists who regularly perform peribulbar blocks.

\section{Method}

The data presented were collected for audit purposes over a 3 year period on 1000 consecutive patients having peribulbar blocks for intraocular surgery, and local ethics committee approval was gained before using the data. The local anaesthetic technique used was a two-injection transconjunctival peribulbar block. The conjunctiva was first anaesthetised with $0.4 \%$ oxybuprocaine and $1 \%$ amethocaine drops. A 'painless local' injection of $1 \mathrm{ml}$ $0.2 \%$ lignocaine in balanced salt solution using a $27 \mathrm{G}$ $18 \mathrm{~mm}$ needle into the subconjunctival space of the inferotemporal region was used in 499 patients to anaesthetise for the peribulbar injection (Fig. 1). The peribulbar block was administered using a $25 \mathrm{G} 25 \mathrm{~mm}$ sharp needle with the patient's eye in the primary gaze position. The first injection was in the inferotemporal region at the junction of the medial two-thirds and lateral third of the orbital rim and the second injection medial to the caruncle. The local anaesthetic solution used was lignocaine 2\% with 1:200 000 adrenaline. Hyaluronidase $30 \mathrm{IU} / \mathrm{ml}$ was added and all solutions were warmed to body temperature. After injection the eye was compressed using a Honan balloon inflated to a pressure of $30 \mathrm{mmHg}$. The intraocular pressure (IOP) was measured with a Tono-Pen (Mentor O\&O) ${ }^{6}$ pre-injection,

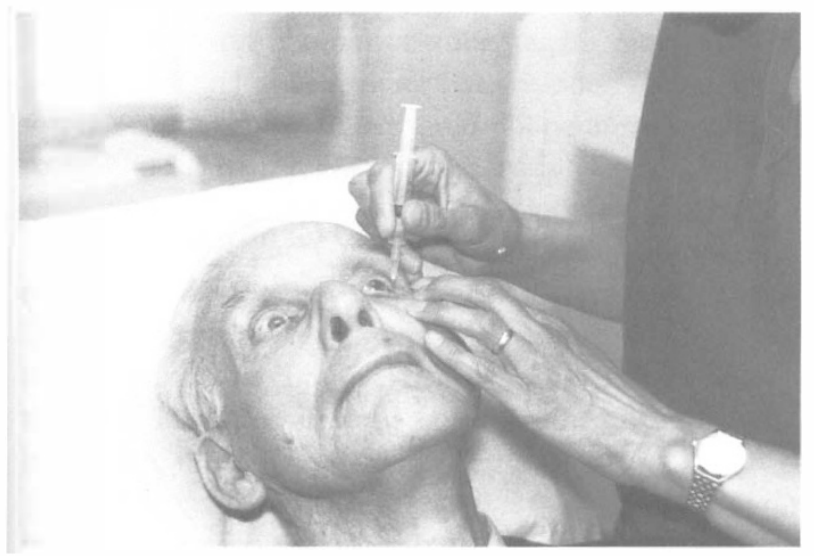

Fig. 1. Administration of a 'painless local' injection of lignocaine in balanced salt solution into the subconjunctival space of the inferotemporal region.
Table 1. Person performing block

\begin{tabular}{lc}
\hline & \% of blocks done \\
\hline Consultant anaesthetist & 77.2 \\
Trainee anaesthetist & 14.0 \\
Staff grade anaesthetist & 3.2 \\
Surgeon & 5.6 \\
\hline
\end{tabular}

immediately post-injection and 5 and $10 \mathrm{~min}$ postinjection. The eye and eye lids were observed for movement and supplementary injections were given if there was still excessive movement of the eye at $10 \mathrm{~min}$. Audit data collected at the time of surgery included the person performing the block, the volume of local anaesthetic injected, the number of supplemental injections and the IOP. The movement of the eye during surgery was rated by the surgeon as nil, moderate or large. Visual rating scores for pain of injection and pain of surgery, using a 10-point scale where 0 is equivalent to no pain and 10 to the worst pain ever, were completed after surgery when the patient had returned to the day case unit. Any complications as a result of the block were recorded.

Age data were analysed using Student's $t$-test. A chi-squared test was used to analyse sex distribution, complication rate and reinjection rate. The visual rating scores for pain were compared using the Mann-Whitney $U$-test. A $p$ value of less than 0.05 was taken as significant.

\section{Results}

All 1000 patients had blocks with lignocaine $2 \%$ and 1:200 000 adrenaline. The mean age of the group was 75 years (range 26-96 years), with 631 female and 369 male patients. Consultant anaesthetists performed the majority of blocks. The remainder were performed by trainee anaesthetists, staff grade anaesthetists or by the operating surgeon with an anaesthetist in attendance (Table 1). The mean volume of solution injection was $10 \mathrm{ml}$ (range 5-16 ml). Supplementary injections were required in $17.2 \%$ of patients. The reinjection rate for trainees was slightly higher than that of consultant anaesthetists but this difference was not significant (Table 2). IOP measurements showed an initial rise in IOP followed by a rapid fall to below baseline level after application of the Honan balloon (Table 3).

Akinesia was achieved in $79 \%$ of blocks (Table 4 ). The most frequent complication was chemosis (conjunctival oedema), which occurred in $10 \%$ of blocks. Trainee anaesthetists had a slightly higher incidence of chemosis $(12.1 \%)$ compared with consultants $(8.4 \%)$ but this difference was not significant. Other complications

Table 2. Reinjection rate

\begin{tabular}{lc}
\hline & $\%$ \\
\hline Consultant anaesthetist & 17.5 \\
Trainee anaesthetist & 20.7 \\
Staff grade anaesthetist & 9.4 \\
Surgeon & 5.4 \\
\hline
\end{tabular}




\begin{tabular}{lc}
\hline & Mean (SD) $\mathrm{mmHg}$ \\
\hline Pre-injection & $18.2(6.1)$ \\
Immediately post-injection & $22.6(10.3)$ \\
Five minutes post-injection & $13.5(5.9)$ \\
Ten minutes post-injection & $12.8 \quad(6.1)$ \\
\hline
\end{tabular}

included 9 minor peribulbar haemorrhages and peribulbar bruising in 24 patients, none of which interfered with surgery. There were no major life- or sight-threatening complications, in particular no globe perforations. For analysis of pain scores the larger group was divided into two smaller groups. Group $1(n=499)$ had a 'painless local' subconjunctival injection and group $2(n=501)$ did not. The age and sex characteristics of these two groups were not significantly different. Although the pain scores were low in both groups, the use of the 'painless local' in group 1 resulted in significantly lower scores for pain of injection $(p<0.05$, Mann-Whitney $U$ ). Scores for pain of injection are shown in Fig. 2, with a higher proportion of patients in group 1 reporting lower pain scores and greater numbers of patients in group 2 with scores of 5 and above. Intraoperative pain scores were not statistically significantly different between the two groups, as is illustrated in Fig. 3.

\section{Discussion}

This study of recent experience of a local anaesthesia service for eye surgery is based on audit data collected at the time of surgery and the results are not those of a controlled clinical trial. However, we feel that the results contribute particularly to a discussion of the safety, efficacy and acceptability of the peribulbar block.
Table 4. Eye movement

\begin{tabular}{lc}
\hline & $\%$ \\
\hline None & 79.3 \\
Small & 15.5 \\
Moderate & 4.7 \\
Large & 0.5 \\
\hline
\end{tabular}

\section{Safety}

The peribulbar block is considered a safer technique than the retrobulbar block because the needle does not enter the muscle cone, ${ }^{4,7}$ although major complications such as globe perforation and brain stem anaesthesia may occur. A recent survey of ophthalmologists in the UK, however, suggested that the incidence of globe perforation during peribulbar block was higher than previously reported. ${ }^{8}$ In our series of 1000 peribulbar blocks there were no incidents of globe perforation and all reported complications were minor. This is despite the fact that $14 \%$ of blocks were done by anaesthetists in training. This low incidence of major complications may be the result of a combination of factors. The first is that of training. It is frequently stated that those performing peribulbar blocks must be well trained in the technique and have a thorough understanding of the relevant anatomy. ${ }^{5,9-11}$ In this establishment anaesthetic trainees are taught the technique by two consultant anaesthetists with many years' experience. This includes the use of a skull to demonstrate needle position, practical demonstration and close supervision of the trainees while performing the block. Secondly, the risk of globe perforation is increased in patients with higher axial lengths. ${ }^{12}$ Duker et al. ${ }^{13}$ estimated the risk of globe perforation during local anaesthesia with the eye axial length greater than $26 \mathrm{~mm}$ as 1 in $140 .{ }^{13}$ Hamilton et al. ${ }^{3}$ stated that it is a safe prerequisite to have an axial length measurement prior to a regional eye block. ${ }^{3}$ This is

\section{Pain of injection scores}

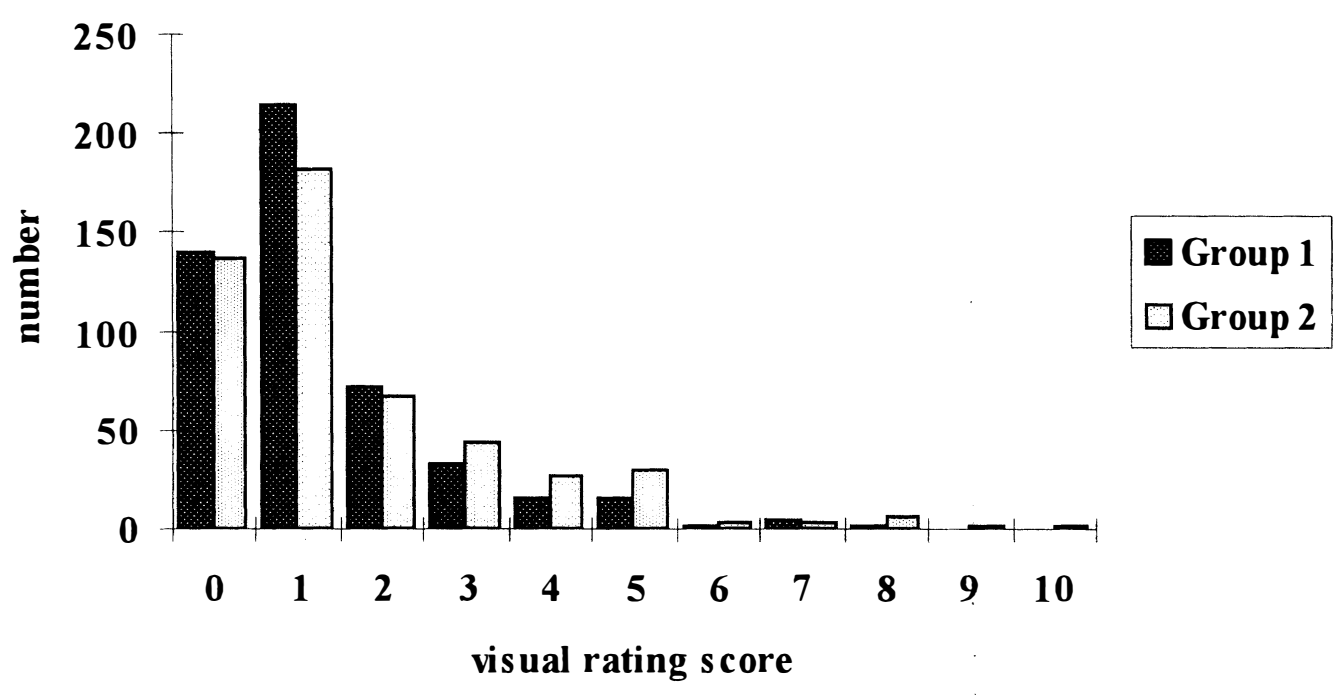

Fig. 2. Scores for the pain of injection. Group $1(\mathrm{n}=499)$ had a 'painless local' subconjunctival injection, group $2(\mathrm{n}=501)$ did not. 


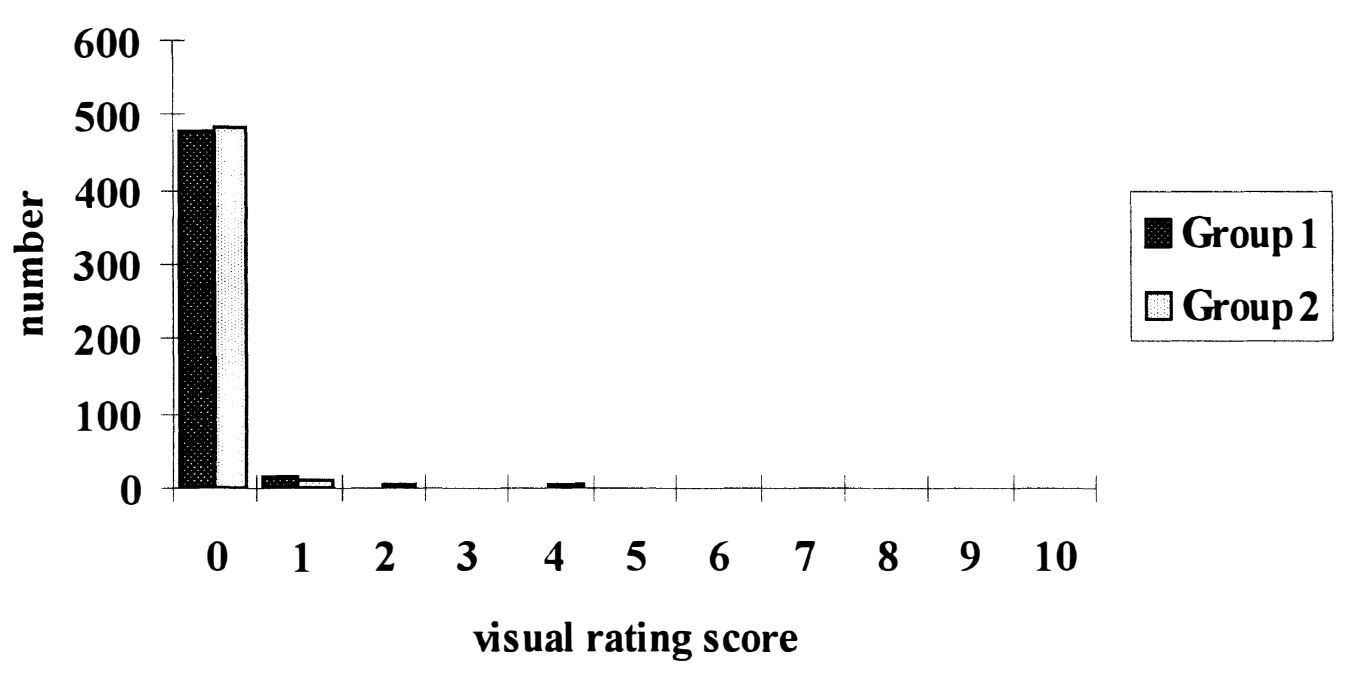

Fig. 3 Intraoperative pain scores. Group $1(\mathrm{n}=499)$ had a 'painless local' subconjunctival injection, group $2(\mathrm{n}=501)$ did not.

routine practice in our establishment, where patients with an axial length greater than $26 \mathrm{~mm}$ are not refused regional anaesthesia but their peribulbar block is performed by a consultant anaesthetist. Finally we believe that a well-organised day case ophthalmic service with particular regard to the selection and preparation of patients contributes to patient safety, and also greatly reduces the need for patient sedation which itself may be hazardous. The most frequent complication recorded was chemosis. This is in part caused by the large volume of local anaesthetic used for the peribulbar block. It usually subsides after application of the Honan balloon and rarely interferes with surgery. Its incidence is thought to reduce with increasing experience of the person giving the block. In this series there was a lower incidence of chemosis in blocks given by consultants compared with trainees but this difference was not significant.

The use of peribulbar blocks in patients taking anticoagulants has been the subject of debate. There is a risk of life-threatening complications if anticoagulants are stopped, which has to be balanced against the risk of intraocular or retrobulbar haemorrhage if they are continued. The Joint Working Party report ${ }^{2}$ recommends that the prothrombin time should not be more than twice control and there appears to be a body of opinion that considers the risk of bleeding, especially when smallincision surgery and peribulbar blocks are used, to be much less than the risk of discontinuing anticoagulants. ${ }^{14}$ The risk of sight-threatening haemorrhage may be minimised further if topical or sub-Tenon's anaesthesia is used. We have encountered no problems in performing blocks in patients taking anticoagulants.

The inherent danger of peribulbar blocks is due to the use of sharp needles placed close to the globe. Nonneedle techniques such as the sub-Tenon block and topical anaesthesia carry a negligible risk of globe perforation. These techniques have their own limitations but it is likely that their use will increase as a result of their greater safety in comparison with the peribulbar block.

\section{Efficacy}

The goals of regional anaesthesia for cataract extraction have been described as globe and conjunctival anaesthesia, globe, lid and periorbital muscle akinesia, and orbit and globe hypotension. ${ }^{15}$ Globe and conjunctival anaesthesia in this series of blocks may be assessed by the results of the visual rating scores for intraoperative pain. These show very low scores indicating good anaesthesia. The production of an akinetic eye is important in creating optimal operating conditions. The method used for assessing eye movement in this series was relatively subjective compared with previously described methods. ${ }^{16}$ However, the assessment was made by the operating surgeon and should reflect the operating conditions experienced. The result of this assessment showed a reasonably high rate of akinesia using lignocaine as the local anaesthetic and surgery was still possible in those eyes with large amounts of movement. A further indicator of efficacy of the block is the requirement for supplemental injections. Recorded rates for supplemental injections vary widely, for example 5-63\%. ${ }^{4,17}$ Factors influencing this include the experience of the person administering the block and the local anaesthetic used, but also the tolerance of the operating surgeon of any eye movement. In this series of blocks trainees did have a higher rate of supplemental injections but not significantly so. In our practice we have not found the shorter duration of action of lignocaine compared with bupivacaine to be a problem and surgery is generally completed within $40 \mathrm{~min}$ from the start of the block. Low IOP is desirable during intraocular surgery and ocular compression devices are effective in 
producing this. ${ }^{18}$ Our results are in agreement with the findings of previous studies that the IOP increases after initial injection and then falls to below baseline after application of an orbital compression device. ${ }^{18-20}$ From the audit data collected, we were unable to distinguish those patients having surgery for glaucoma from those having cataract surgery. Typically $90 \%$ of surgery is for cataracts and $10 \%$ for glaucoma. The values of IOP measured may be influenced by the patient's eye pathology.

\section{Acceptability}

Having intraocular surgery performed as a day case under local anaesthesia appears to be well accepted by patients. This must be influenced in part by relatively pain-free injections. The use of perconjunctival injections and warm solutions has been shown to reduce pain ${ }^{21,22}$ and the 'painless local' injection has been recommended to produce a pain-free injection. ${ }^{15,23}$ The results from these data show that the 'painless local' injection does result in significantly lower scores for pain of injection. Balanced salt solution in which the local anaesthetic is diluted contains $\mathrm{NaCl} 0.64 \%, \mathrm{KCl} 0.075 \%, \mathrm{CaCl}_{2}$ 0.048\%, $\mathrm{MgCl}_{2} 0.03 \%$, sodium acetate $0.39 \%$ and sodium citrate $0.17 \%$ in sterile water with a $\mathrm{pH}$ adjusted to neutral. When used to dilute lignocaine for intradermal injections it produces a pain-free injection. ${ }^{24}$ Buffering local anaesthetic solutions has been shown to reduce pain felt on injection, ${ }^{25}$ and the dilution of balanced salt solution to a mixture of lignocaine and adrenaline will raise its $\mathrm{pH}$ so providing a solution that is not only relatively painfree to inject but that also anaesthetises for the subsequent peribulbar injection.

In conclusion, our experience of the peribulbar block suggests that this is a safe, effective method of providing anaesthesia for eye surgery provided that it is taught methodically and practised by experienced staff. The use of a 'painless local' subconjunctival injection produces less pain felt on injection and we would endorse the recommendations for its use.

\section{References}

1. Davis DB IInd, Mandel MR. Posterior peribulbar anesthesia: an alternative to retrobulbar anesthesia. J Cataract Refract Surg 1986;12:182-5.

2. Report of the Joint Working Party on Anaesthesia in Ophthalmic Surgery. London: Royal College of Anaesthetists, College of Ophthalmologists, 1993.

3. Hamilton R, Gimbel H, Strunin L. Regional anaesthesia for 12000 cataract extraction and intraocular lens implantation procedures. Can J Anaesth 1988;35:615-23.
4. Davis DB IInd, Mandel MR. Efficacy and complication rate of 16224 consecutive peribulbar blocks: a multicenter study. J Cataract Refract Surg 1994;20:327-37.

5. Boase DL. Local anaesthesia revisited. Eye 1996;10:531-2.

6. Boothe WA, Lee DA, Panek WC, Pettit TH. The Tono-Pen: a manometric and clinical study. Arch Ophthalmol 1988;106:1214-7.

7. Rubin AP. Complications of local anaesthesia for ophthalmic surgery. Br J Anaesth 1995;75:93-6.

8. Gillow JT, Aggarwal RK, Kirkby GR. A survey of ocular perforation during ophthalmic local anaesthesia in the United Kingdom. Eye 1996;10:537-8.

9. Gillow JT, Aggarwal RK, Kirkby GR. Ocular perforation during peribulbar anaesthesia. Eye 1996;10:533-6.

10. Troll G. Regional ophthalmic anaesthesia: safe techniques and avoidance of complications. J Clin Anaesth 1995;7:163-72.

11. Grizzard WS, Kirk NM, Pavan PR, Antworth MV, Hammer ME, Roseman RL. Perforating ocular injuries caused by anesthesia personnel. Ophthalmology 1991;98:1011-6.

12. Churchill AJ, James TE, Lacey V. Should myopes have routine axial length measurements before retrobulbar or peribulbar injections? Br J Ophthalmol 1996;80:498.

13. Duker JS, Belmont JB, Benson WE, et al. Inadvertent globe perforation during retrobulbar and peribulbar anesthesia. Ophthalmology 1991;98:519-26.

14. Consultation section: Attitudes regarding the concomitant use of anticoagulants with elective cataract surgery. J Cataract Refract Surg 1992;18:531-5.

15. Hamilton RC. Techniques of orbital regional anaesthesia. Br J Anaesth 1995;75:88-92.

16. Saunders DC, Sturgess DA, Pemberton CJ, Morgan LH, Bourne A. Peribulbar and retrobulbar anesthesia with prilocaine: a comparison of two methods of local ocular anesthesia. Ophthalmic Surg 1993;24:842-5.

17. Dopfmer UR, Maloney DG, Gaynor PA, Ratcliffe RM, Dopfmer S. Prilocaine $3 \%$ is superior to a mixture of bupivacaine and lignocaine peribulbar anaesthesia. $\mathrm{Br} \mathrm{J}$ Anaesth 1996;76:77-80.

18. Bowman R, Liu C, Starkies N. Intraocular pressure changes after peribulbar injections with and without ocular compression. Br J Ophthalmol 1996;80:394-7.

19. Meyer D, Hamilton RC, Loken RG, Gimbel HV. Effect of combined peribulbar and retrobulbar injection of large volumes of anesthetic agents on the intraocular pressure. Can J Ophthalmol 1992;27:230-2.

20. Demediuk OM, Dhaliwal RS, Papworth DP, Devenyi RG, Wong DT. A comparison of peribulbar and retrobulbar anesthesia for vitreoretinal surgical procedures. Arch Ophthalmol 1995;113:908-13.

21. Sweeney EJ, Barber K, Prosser JA. A comparison of percutaneous and perconjunctival routes of administration of peri-ocular anaesthesia for day case cataract surgery. Anaesthesia 1993;48:336-8.

22. Ursell PG, Spalton DJ. The effect of solution temperature of the pain of peribulbar anesthesia. Ophthalmology 1996;103:839-41.

23. Rubin AP. Anaesthesia for cataract surgery: time for change? Anaesthesia 1990;45:717-8. 